\title{
The Protective Biochemical Properties of Arbuscular Mycorrhiza Extraradical Mycelium in Acidic Soils Are Maintained throughout the Mediterranean Summer Conditions
}

\author{
Jorge M. S. Faria ${ }^{1,2, *(\mathbb{D}}$, Dora Martins Teixeira ${ }^{3,4}$, Ana Paula Pinto ${ }^{2,4}$, Isabel Brito ${ }^{2,4}$, Pedro Barrulas ${ }^{3}$ and \\ Mário Carvalho ${ }^{2,4}$ \\ 1 INIAV, I.P., National Institute for Agricultural and Veterinary Research, Quinta do Marquês, \\ 2780-159 Oeiras, Portugal \\ 2 MED, Mediterranean Institute for Agriculture, Environment and Development, Institute for Advanced \\ Studies and Research, Évora University, Pólo da Mitra, Ap. 94, 7006-554 Évora, Portugal; \\ app@uevora.pt (A.P.P.); ibrito@uevora.pt (I.B.); mjc@uevora.pt (M.C.) \\ 3 HERCULES Laboratory, Évora University, Largo Marquês de Marialva 8, 7000-809 Évora, Portugal; \\ dmt@uevora.pt (D.M.T.); pbarrulas@uevora.pt (P.B.) \\ 4 Science and Technology School, Évora University, Rua Romão Ramalho 59, 7000-671 Évora, Portugal \\ * Correspondence: fariajms@gmail.com
}

check for updates

Citation: Faria, J.M.S.; Teixeira, D.M.; Pinto, A.P.; Brito, I.; Barrulas, P.; Carvalho, M. The Protective Biochemical Properties of Arbuscular Mycorrhiza Extraradical Mycelium in Acidic Soils Are Maintained throughout the Mediterranean Summer Conditions. Agronomy 2021, 11, 748. https://doi.org/ 10.3390/agronomy11040748

Academic Editor: John P. Thompson

Received: 15 March 2021

Accepted: 9 April 2021

Published: 12 April 2021

Publisher's Note: MDPI stays neutral with regard to jurisdictional claims in published maps and institutional affiliations.

Copyright: (c) 2021 by the authors. Licensee MDPI, Basel, Switzerland. This article is an open access article distributed under the terms and conditions of the Creative Commons Attribution (CC BY) license (https:// creativecommons.org/licenses/by/ $4.0 /)$.
Abstract: In acidic soils with manganese (Mn) toxicity, arbuscular mycorrhizal fungi (AMF) can improve plant host growth by enhancing nutrition and protecting against environmental stress. The intact extraradical mycelium (ERM) of AMF is able to survive Mediterranean summer conditions and provide an earlier colonization of winter crops. This study evaluated if summer season conditions hindered the beneficial effects of wheat colonization by the intact ERM associated with a native plant, in acidic soil. Wheat was grown in soil with intact or disrupted ERM associated with Ornithopus compressus (ORN), developed for 7 or 24 weeks, to simulate ERM summer survival. The activity of antioxidant enzymes was determined, and the quantitative analysis of Mn and macronutrients was performed by inductively coupled plasma mass spectrometry (ICP-MS), in wheat shoots and respective subcellular fractions. Wheat colonization by intact ERM decreased shoot Mn concentration but increased the proportion of $\mathrm{Mn}$ in the apoplast. Overall, antioxidant enzymatic activity decreased but the proportion of Mn-superoxide dismutase activity over the remaining isoforms increased, suggesting its important role in the AMF-mediated mitigation of Mn toxicity. Summer conditions did not substantially reduce the benefits provided by ORN ERM. A no-till strategy allied to the development of native microbiota can contribute to the sustainable optimization of acidic soil use.

Keywords: acidic soil; apoplast; arbuscular mycorrhizal fungi; element compartmentalization; extraradical mycelium; manganese superoxide dismutase; manganese toxicity; Ornithopus compressus; sustainable soil management; Triticum aestivum

\section{Introduction}

Soil acidity is a worldwide agroecological concern due to the associated rise in aluminum ( $\mathrm{Al})$, iron (Fe) and/or manganese (Mn) bioavailability to plant toxic levels. In southern Portugal, acidic Cambisols and Arenosols can frequently display toxic levels of bioavailable $\mathrm{Mn}\left(\mathrm{Mn}^{2+}\right)$, which often becomes a major constraint to crop productivity [1]. In this region, several crops reportedly exhibited symptoms of Mn toxicity due to a high $\mathrm{Mn}$ bioavailability combined with a low shoot magnesium $(\mathrm{Mg}) / \mathrm{Mn}$ ratio [2,3]. Low $\mathrm{Mg} / \mathrm{Mn}$ ratios can induce $\mathrm{Mn}$ competition for $\mathrm{Mg}$ active sites in vital cellular processes, which prevents enzymes from performing their functional roles and induces oxidative stress $[4,5]$. In acidic soils, Mn bioavailability can be further amplified by waterlogging events or large inputs of chemical fertilizers, used in extensive farming systems [6,7]. To prevent crop yield 
losses due to Mn toxicity, liming with dolomitic lime (calcium (Ca) and $\mathrm{Mg}$ carbonates) is a widely used agricultural practice. Dolomitic lime acts by increasing soil $\mathrm{pH}, \mathrm{Ca}$ and $\mathrm{Mg}$ concentrations (competitors for plant Mn transporters) but also by increasing soil carbonate concentration. Nevertheless, liming increases production costs, alters soil biochemistry and was reported to be frequently applied in undereffective amounts [8-10].

In the search for more sustainable and eco-efficient agricultural practices, the use of beneficial plant microbes, such as arbuscular mycorrhizal fungi (AMF), has shown a great potential to increase crop productivity in acidic soils with Mn toxicity. AMF establish the oldest and most widespread mutualistic association between plants (ca. $80 \%$ of plants species) and soil microbes. Colonization of host vascular plants occurs when AMF hyphae penetrate the root cortical cells and establish arbuscles and/or vesicles. The host plant benefits from increased uptake of water and immobile soil nutrients, for example, phosphorus $(\mathrm{P})$, while the colonizing fungi receive photosynthates (carbohydrates) and lipids from the plant [11]. This symbiotic relation has shown the potential to reduce metal toxicity and simultaneously increase productivity of their host plants [12-15]. Symbiotic microorganisms indigenous to acidic soils are generally adapted and show increased tolerance to metal stress [16-18]. In these environments, symbiotic AMF play pivotal roles in plant survival [19-21]. By growing native stress-adapted plants (i.e., Developers) before the target crop, a beneficial microbial environment can be established in the acidic soil capable of improving crop growth and protecting against Mn toxicity [22,23]. AMF are responsible for a considerable part of these protective effects, given that crop protection is considerably higher when promoted by highly mycotrophic native plants, growing under Mn toxicity in acid soils [24,25]. In addition, intact extraradical mycelium (ERM), developed from AMF associated with the roots of strongly mycotrophic Developers is able to colonize the succeeding crop in earlier stages of plant development, when compared to AMF spores or root fragments, as the main inoculum sources. In these conditions, plant growth can be improved and toxic Mn contents decreased, revealing the benefits of a fully established intact ERM as a preferential inoculum source for mycorrhizal colonization [22]. In winter wheat (Triticum aestivum L.), growth improvement is dependent on the previous Developer plant. For example, in wheat plants grown after Ornithopus compressus L. (ORN) native Developer, shoot dry weight increased almost 2-fold when compared to those grown after Lolium rigidum L., despite having similar Mn concentrations, which suggests the presence of functional diversity in ERM associated with different native plants [24]. In these systems, a greater AMF diversity has been identified in ORN roots and in the roots of wheat grown after this Developer plant [21,26], which suggests that functional diversity results from different stress-coping mechanisms in the host shoots. In fact, transcriptomic studies revealed that many processes related to cellular division and growth were activated when wheat roots were colonized by intact ERM developed from ORN, and fewer were related to stress responses. In contrast, when L. rigidum was used as the Developer plant, genes related to oxidative stress, disease protection and metal ion binding were mostly induced [27].

Under metal toxicity, symbiotic AMF can induce significant biochemical alterations in the host shoots that counteract metal stress, namely the management of subcellular element distribution and of shoot physiological status, including photosynthesis, phytohormone balance, antioxidant enzymes or nonenzymatic compounds [28-32]. In wheat, Mn toxicity induces the subcellular redistribution of root and shoot $\mathrm{Mg}, \mathrm{Ca}, \mathrm{Mn}$ and P levels. While $\mathrm{Ca}$ seems to accumulate in the root apoplast, $\mathrm{Mn}$ and $\mathrm{P}$ are redirected to the shoot vacuole, probably as a detoxification strategy against excess $\mathrm{Mn}$ and resulting oxidative stress [33].

In Mediterranean conditions, the summer season is characterized by a dry climate with high temperatures and reduced plant soil coverage that can influence the survival and infectivity of the developed ERM. However, ERM developed in association with winter wheat can survive the summer season and retain its capability to colonize the next season crop [34]. 
To assess if the protective effect of intact ERM against Mn toxicity can be associated with its summer survival, for the promotion of plant growth, winter wheat was grown in (a) a disturbed or undisturbed acidic Cambic soil, after (b) freshly developed ERM (i.e., for 7 weeks) or ERM developed in the previous season and kept in dry soil over summer season (i.e., for 24 weeks). ERM was developed by the soil indigenous AMF associated with ORN, known to confer a high degree of protection against Mn toxicity in wheat [24]. This allowed the evaluation of soil disturbance (tillage) and ERM summer survival on the maintenance of ERM protective effects in wheat grown under excessive levels of Mn. The protection induced by the ERM was analysed by determining wheat shoot dry weight (DW); $\mathrm{Mg}, \mathrm{Ca}, \mathrm{Mn}$ and P redistribution; element compartmentalization and oxidative status. This study determined the ability of ORN ERM to provide a similar degree of protection, before and after the dry Mediterranean summer season. In the framework of sustainable soil management, this study provides an important contribution for the optimization of crop production under eco-efficient agricultural practices that further promote soil health.

\section{Materials and Methods}

\subsection{Plant Material and Experimental Protocol}

The granitic Eutric Cambisol was collected from the top $20 \mathrm{~cm}$ of the headland for a long-term natural pasture at Mitra Farm, Évora University, Alentejo, Portugal $\left(38^{\circ} 32^{\prime} \mathrm{N} ; 08^{\circ} 00^{\prime} \mathrm{W}\right)$. The air-dried and sieved (soil sieves with stainless-steel mesh of $2 \mathrm{~mm}$ pore and steel frame with $20 \mathrm{~cm}$ of diameter) acidic soil contained $23 \mathrm{mg}$ $\mathrm{P} / \mathrm{kg}$ (Egner-Rhiem), $44 \mathrm{mg} \mathrm{K} / \mathrm{kg}, 0.4 \mathrm{mg} \mathrm{N}-\mathrm{NO}_{3} / \mathrm{kg}, 29 \mathrm{mg} \mathrm{Mg} / \mathrm{kg}, 22.6 \mathrm{mg} \mathrm{Mn} / \mathrm{kg}$ (DTPA-diethylenetriaminepentaacetic acid), $9 \mathrm{~g} \mathrm{SOM}$ (soil organic matter) $/ \mathrm{kg}$ and $\mathrm{pH}$ 5.6 (soil: water $=1: 2.5(w / v)$ ) [33]. Acidic soil had 180 viable arbuscular mycorrhizal fungi (AMF) propagules per gram of dry soil, according to [24]. Five pregerminated Ornithopus compressus (ORN) seeds were grown in $8 \mathrm{~L}$ pots packed with the acidic soil, with its naturally occurring indigenous AMF population, to naturally develop mycorrhizal colonization and respective ERM [21]. Two ERM development periods were established; namely, (i) ERM developed by growing ORN for 7 weeks, and (ii) ERM developed from ORN grown in the previous season, keeping the pots during dry summer season (for 24 weeks). This 24-week period treatment replicated ERM survival through Mediterranean summer conditions [34]. A negative control (without the previous growth of ORN, i.e., 0 weeks of ORN growth) was also included. For the disturbed soil treatment, after each respective growth period, Developer plants were eliminated with herbicide according to [24], and the soil was disturbed to disrupt Developer ERM [23]. Soil in the disturbed treatment had spores, colonized roots fragments and disturbed ERM as a main source of AMF propagules, while in undisturbed soil colonization was preferentially initiated from intact ERM [21]. Summarizing, five experimental treatments were established: (1) No previous growth of ORN; (2) 7 weeks' growth of ORN, undisturbed; (3) 7 weeks' growth of ORN, disturbed; (4) 24 weeks' growth of ORN, undisturbed; and (5) 24 weeks' growth of ORN, disturbed. Soil was rewetted before planting wheat seedlings, and manual weeding was performed daily for wild weed species occurring naturally in the field soil. Six wheat seedlings (Triticum aestivum L. cv. Ardila) were planted per pot, after being germinated for 3 days on wet paper in a tray, covered with plastic film to avoid desiccation. Throughout the experiment, pots were kept fully randomised in a greenhouse, weighed every day and watered with deionised water, approximately to $70 \%$ of maximum water holding capacity, by weight. Minimum and maximum air temperatures were recorded daily, and temperature control of the greenhouse was set to a maximum of $30^{\circ} \mathrm{C}$. After three weeks, wheat plants (four replicates) were collected, and the shoots were weighed and immediately frozen in liquid nitrogen and stored at $-80^{\circ} \mathrm{C}$ until analysis. 


\subsection{Wheat Shoots Subcellular Partitioning}

Wheat shoot subcellular element distribution was determined according to $[35,36]$ with some modifications. Briefly, frozen wheat shoots were ground to a fine powder in liquid nitrogen using a melamine pestle and mortar, and were homogenized in buffer solution (250 mM sucrose, $1.0 \mathrm{mM}$ dithioerythritol and $50 \mathrm{mM}$ Tris- $\mathrm{HCl}(\mathrm{pH} 7.5))$ in a ratio of $200 \mathrm{mg} / 5 \mathrm{~mL}$ buffer solution. The homogenate was centrifuged at $2500 \times g$ for $15 \mathrm{~min}$, at $4{ }^{\circ} \mathrm{C}$. The pellet obtained, mainly comprising cell walls, cellular debris and metal granules (i.e., metal deposits that can occur near the cell wall of some plants), was defined as the cell wall fraction (CWF). The supernatant was then centrifuged at $100,000 \times g$ for $60 \mathrm{~min}$, at $4{ }^{\circ} \mathrm{C}$, to isolate microsomes and organelle components (e.g., chloroplasts and mitochondria). The organelle-rich pellet was designated as the organelle fraction (OF), while the supernatant containing the soluble components of the cytosol and vacuole contents (e.g., antioxidant enzymes and metal-binding compounds such as phytochelatins and metallothioneins) was designated as the vacuole fraction (VF). All fractions were kept at $-80^{\circ} \mathrm{C}$ until analysis.

\subsection{Multi-Element Analysis of Wheat Shoots and Subcellular Fractions}

$\mathrm{Ca}, \mathrm{P}, \mathrm{Mg}$ and $\mathrm{Mn}$ were quantified by inductively coupled plasma mass spectrometry (ICP-MS), in shoots, and respective subcellular fractions, of wheat grown for three weeks in disturbed or undisturbed soil from previously grown ORN, for 0, 7 or 24 weeks [33].

\subsubsection{Sample Digestion}

Ground shoot samples (50 mg), and respective subcellular fractions, were lyophilized in a Telstar LyoQuest lyophilizer for three days. Lyophilized samples were kept overnight in Teflon beakers with $2 \mathrm{~mL}$ of $\mathrm{HNO}_{3}$ (Suprapur, 67-69\%, Fisher Chemicals, Hampton, NH, USA), at room temperature, to increase digestion efficiency. The solutions were then heated $\left(<120{ }^{\circ} \mathrm{C}\right.$ ) for $24 \mathrm{~h}$. To further digest organic material, $0.5 \mathrm{~mL}$ of $\mathrm{H}_{2} \mathrm{O}_{2}$ (Suprapur, $30 \%$, Merck, KGaA, Darmstadt, Germany) were added, and the resulting solutions were heated again at $80^{\circ} \mathrm{C}$. The process was repeated until a clear solution with no precipitates was obtained. After complete digestion, samples were dried at $100^{\circ} \mathrm{C}$ and the solid residue was resuspended in a $2 \% \mathrm{HNO}_{3}$ solution $(50 \mathrm{~mL})$ and kept at $4{ }^{\circ} \mathrm{C}$ until analysis. One digestion blank and one certified reference material (NIST SRM 1573a, Tomato leaves) were included in each digestion batch for method validation, namely, evaluation of accuracy and limits of detection for each element.

\subsubsection{Multi-Element Quantification}

Element quantification was performed on an Agilent 8800 Triple Quadrupole ICPMS, equipped with a Micromist nebulizer. Instrument optimization was performed with an Agilent ICP-MS tuning solution, containing $10 \mu \mathrm{g} / \mathrm{L}$ of $\mathrm{Ce}, \mathrm{Co}, \mathrm{Li}, \mathrm{Tl}$, and $\mathrm{Y}$ in a matrix of $2 \% \mathrm{HNO}_{3}$ (Agilent Technologies, Palo Alto, CA, USA). Multi-element certificate standard solution ICP-MS-68B-A (100 mg/L) from High-Purity Standards (Charleston, SC, USA) was used for external calibration. Ruthenium ( $\mathrm{Ru})$, rhodium $(\mathrm{Rh})$ and iridium (Ir) were used as internal standards for the correction of instrumental drift and matrix effect. The collision/reaction cell was set to "no-gas mode" for the quantification of $\mathrm{Mg}$ and $\mathrm{Mn}$, " $\mathrm{O}_{2}$ mode" for the quantification of $\mathrm{P}$ and " $\mathrm{NH}_{3}$ mode" for the quantification of Ca. Plasma gas flow rate was $15 \mathrm{~mL} / \mathrm{min}$, and collision and reaction gases flow rates were $0.5 \mathrm{~mL} / \mathrm{min}$ for $\mathrm{O}_{2}$ and $1.5 \mathrm{~mL} / \mathrm{min}$ for $\mathrm{NH}_{3}$. Analyses were optimized at $1550 \mathrm{~W}$ forward power and $1.1 \mathrm{~L} / \mathrm{min}$ carrier gas flow with no dilution or makeup gas. Sampling depth $(10 \mathrm{~mm})$ and lens parameters were optimized for highest signal and optimum peak shape while maintaining low oxides and doubly charged species. All the operation modes were performed with the MS/MS scan type. 


\subsection{Wheat Shoot Antioxidant Enzymatic Activity}

Frozen wheat shoot samples $(50 \mathrm{mg})$ were ground to a fine powder with a mortar and pestle (at $\left.4{ }^{\circ} \mathrm{C}\right)$, homogenized in $1 \mathrm{~mL}$ of $50 \mathrm{mM}$ potassium phosphate buffer ( $\left.\mathrm{pH} 7.0\right)$ and centrifuged at $12,000 \times g$ and $4{ }^{\circ} \mathrm{C}$ for $20 \mathrm{~min}$ [37]. The supernatant was used immediately for protein quantification and determination of ascorbate peroxidase (APX), catalase (CAT), glutathione reductase (GR), guaiacol peroxidase (GPX) and superoxide dismutase (SOD) and Mn-SOD activities. Absorbances of four experimental replicates were recorded in a Multiskan Microplate Spectrophotometer (Thermo Scientific, Waltham, MA, USA), each with three instrumental replicates. Protein content was determined against a bovine serum albumin (BSA) calibration curve using Bradford reagent [38]. APX activity was determined according to [39] and [40]. Ascorbate oxidation was followed at $290 \mathrm{~nm}$ for $6 \mathrm{~min}$, and enzyme activity was expressed as $\mu \mathrm{g}$ ascorbate oxidized $/ \mathrm{min} / \mathrm{mg}$ of protein by using an extinction coefficient of $2.8 \mathrm{~L} / \mathrm{mmol} \mathrm{cm}$. CAT activity was determined according to [41]. Hydrogen peroxide decomposition was followed at $240 \mathrm{~nm}$ for $3 \mathrm{~min}$, and enzymatic activity was expressed as $\mu \mathrm{g}_{2} \mathrm{O}_{2}$ decomposed/min/mg of protein by using an extinction coefficient of $39.4 \mathrm{~L} / \mathrm{mol} \mathrm{cm}$. GR activity was determined according to [42] and [43]. Consumption of reduced nicotinamide adenine dinucleotide phosphate (NADPH) was followed at $340 \mathrm{~nm}$ for $3 \mathrm{~min}$, and enzymatic activity was expressed as $\mu \mathrm{g}$ NADPH consumed $/ \mathrm{min} / \mathrm{mg}$ of protein by using an extinction coefficient of $6.2 \mathrm{~L} / \mathrm{mmol} \mathrm{cm}$. GPX activity was determined according to [44]. Formation of guaiacol tetramer (tetraguaiacol) was followed at $470 \mathrm{~nm}$ for $2 \mathrm{~min}$, and enzymatic activity was expressed as $\mu \mathrm{g}$ tetraguaiacol formed $/ \mathrm{min} / \mathrm{mg}$ of protein by using an extinction coefficient of $26.6 \mathrm{~L} / \mathrm{mmol} \mathrm{cm}$. Total SOD activity was determined according to [45]. All reagents were kept under dark conditions, and the reactions were duplicated, with one group being maintained under the dark and the other exposed to light $(15 \mathrm{~W})$ for $15 \mathrm{~min}$. SOD inhibition of formazan formation was determined at $560 \mathrm{~nm}$, and one SOD activity unit (U) corresponded to the enzymatic activity required to inhibit $50 \%$ of NBT photoreduction. Mn-SOD was determined using the methodology described above for SOD activity, with the exception that the protein extract was initially incubated for 30 min with $10 \mathrm{mM} \mathrm{H}_{2} \mathrm{O}_{2}$ to inhibit Fe- and $\mathrm{Cu} / \mathrm{Zn}$-SODs [46]. SOD and Mn-SOD activities were expressed as $\mathrm{U} / \mu \mathrm{g}$ protein.

\subsection{Statistical Analysis}

Statistical analysis was performed with SPSS version 26 statistics software. Statistical significance of data was determined with one-way ANOVA of five treatments by four replicates, using the Tukey's Post-Hoc test for means comparison at a 95\% significance level $(p<0.05)$. The Shapiro-Wilk Test and Browns-Forsythe Test were used for normality and homoscedasticity evaluation, respectively. Results were presented as average and standard error of four biological replicates.

\section{Results}

\subsection{Wheat Growth}

Growth was evaluated by determining wheat shoot dry weight. Wheat grown in the absence of AMF from a Developer plant (i.e., 0 weeks of ORN growth) showed the lowest average shoot DW (Figure 1). 


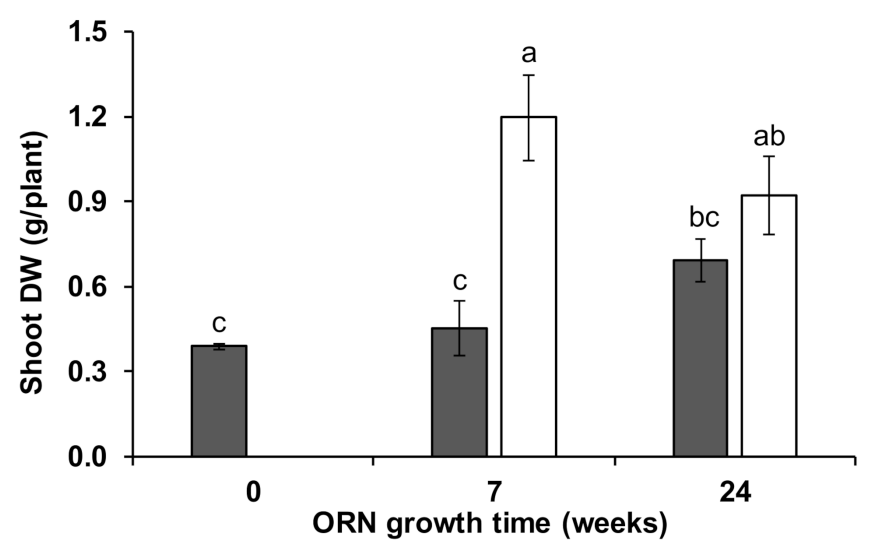

Figure 1. Dry weight (DW, average and standard error) of shoots from wheat plants grown in disturbed (grey columns) or undisturbed (white columns) soil with previously grown Ornithopus compressus (ORN) associated arbuscular mycorrhizal fungi, after 0, 7 or 24 weeks. Different letters indicate statistically significant differences $(p<0.05)$ based on Tukey's test.

Shoots of wheat grown in disturbed soil (where the ERM structure was disrupted), after 7 or 24 weeks of ORN growth, showed no significant differences from control treatment (0 weeks of ORN growth). Shoot DW was significantly higher in wheat grown in undisturbed soil, when compared to disturbed soil.

\subsection{Wheat Shoot Element Composition}

Higher levels of Mn were detected in shoots of wheat grown in the absence of a developer plant ( 0 weeks of ORN growth), reaching $312 \mathrm{mg} / \mathrm{kg}$ shoot DW, a concentration described to induce toxicity in cereals $[24,47]$ (Figure 2a). In comparison to this condition, wheat shoot Mn concentrations were significantly lower in disturbed soil (61 and 56\% decrease, for 7 and 24 weeks of ORN growth, respectively). In the presence of an intact ERM (i.e., undisturbed soil), Mn concentrations were significantly further reduced (78 and $82 \%$ decrease, for 7 and 24 weeks of ORN development, respectively) (Figure 2a). Mg was also detected at significantly lower concentrations in wheat grown in undisturbed soil (Figure $2 \mathrm{~b}$ ); nevertheless, the highest $\mathrm{Mg} / \mathrm{Mn}$ ratios were obtained in shoots of wheat grown in these soils (Figure 2e). Ca content was significantly affected by the time and type of mycorrhization (disturbed and undisturbed soil), whereas P content was affected mostly by the type of mycorrhization (disturbed and undisturbed soil) (Figure 2c,d).

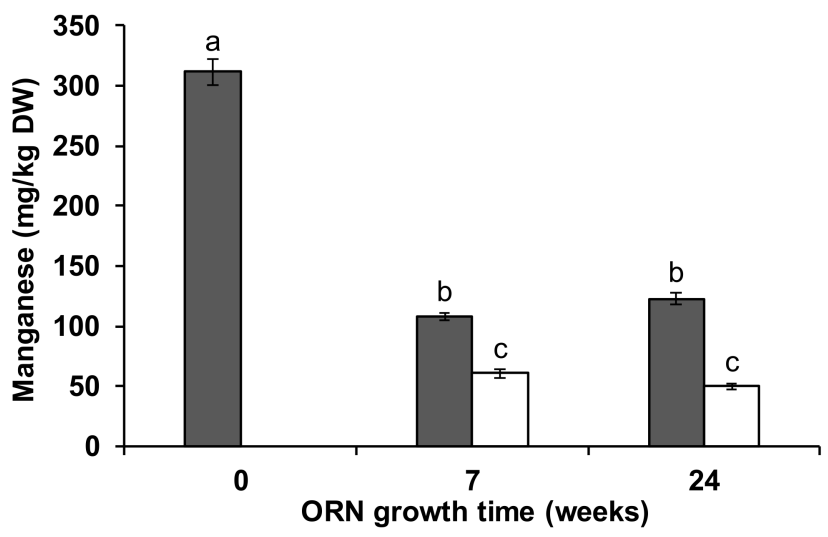

(a)

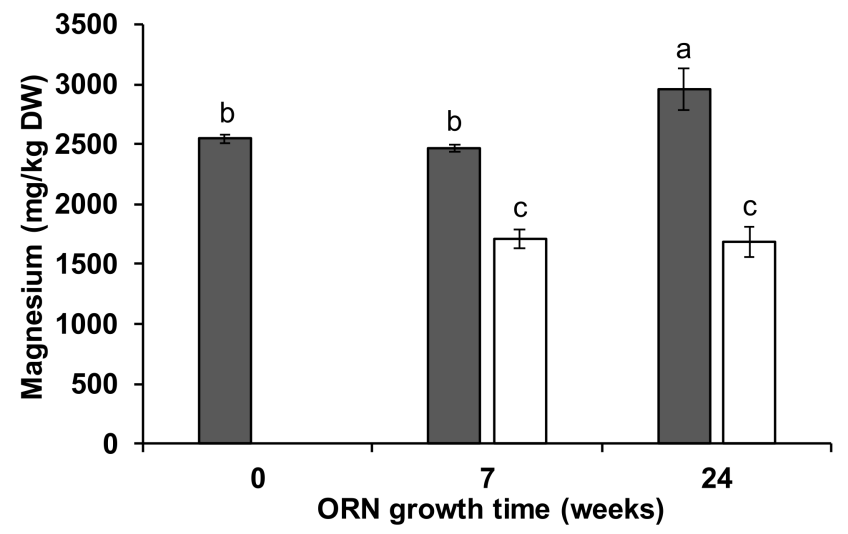

(b)

Figure 2. Cont. 


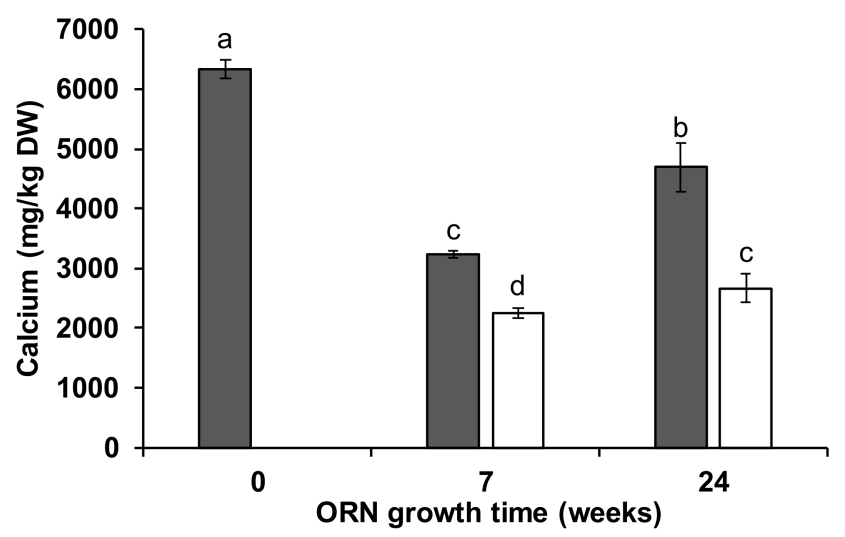

(c)

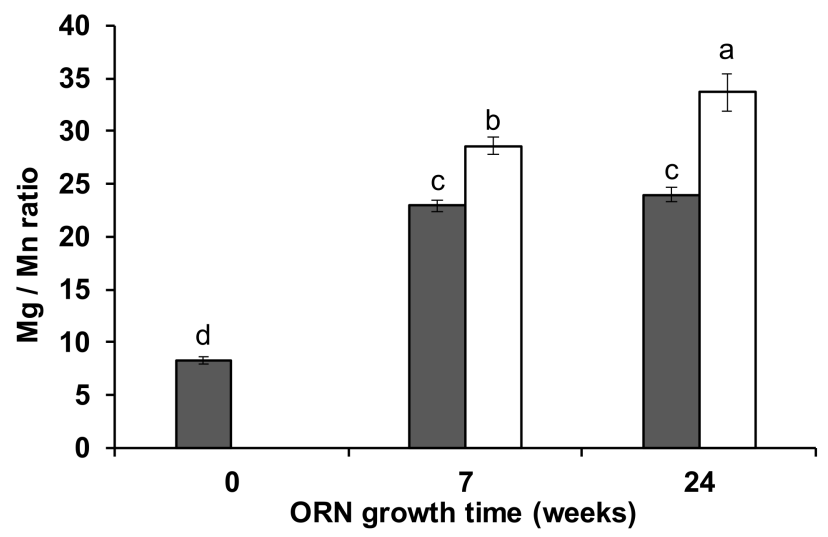

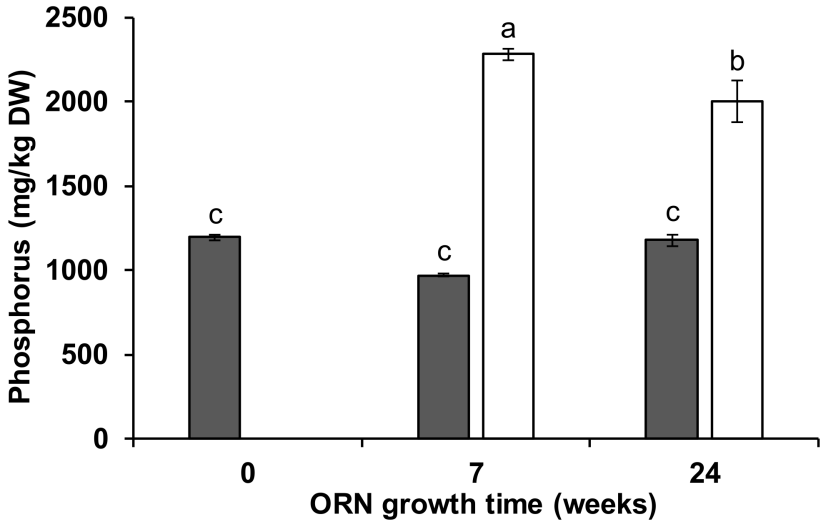

(d)

(e)

Figure 2. Concentrations (average and standard error) of manganese (a), magnesium (b), calcium (c), phosphorus (d) (mg element/kg of shoot dry weight (DW)) and $\mathrm{Mg} / \mathrm{Mn}$ ratios (e) in shoots of wheat grown in disturbed (grey columns) or undisturbed (white columns) soil with previously grown Ornithopus compressus (ORN), after 0, 7 or 24 weeks. Different letters indicate statistically significant differences $(p<0.05)$ based on Tukey's test.

Intracellular element redistribution in wheat shoots was followed to assess Mn evading mechanisms induced by the presence of ORN AMF communities in the acidic soil. Differences in patterns of element distribution were detected for Mn and P (Figure 3 and Supplementary Material). Element proportions are depicted as percentage of element in each subcellular fraction. The shoot cell wall fraction showed a significantly higher percentage of $\mathrm{Mn}$ and $\mathrm{P}$ in wheat grown in the presence of an intact ERM, when compared to a disrupted ERM (i.e., disturbed soil) (Figure 3a,b), suggesting a redistribution of $\mathrm{Mn}$ and $\mathrm{P}$ mediated by intact ERM, in Mn toxicity conditions. When grown in the absence of a previous Developer (i.e., 0 weeks of ORN growth), Mn partitioning pattern was similar to that of the disturbed soil treatment, regardless of Developer growth time, whereas $\mathrm{P}$ showed a different intracellular distribution, probably resulting from non-mycorrhizal P uptake. 


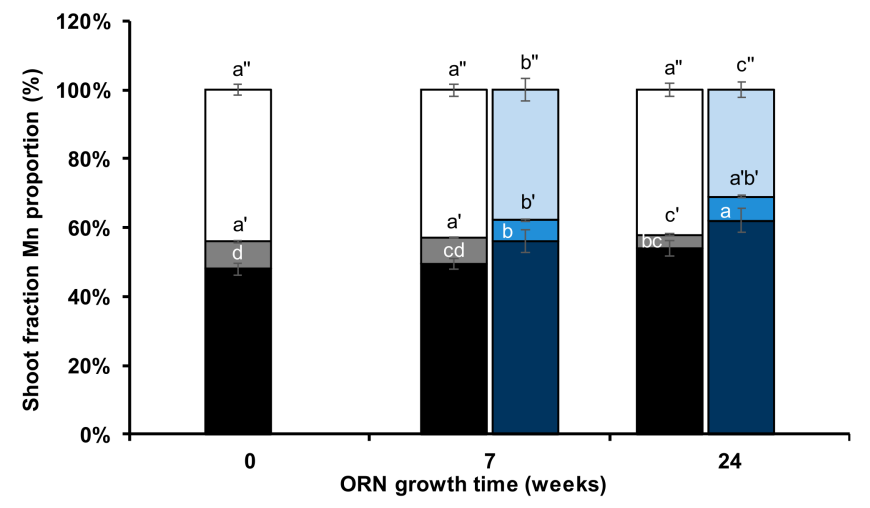

(a)

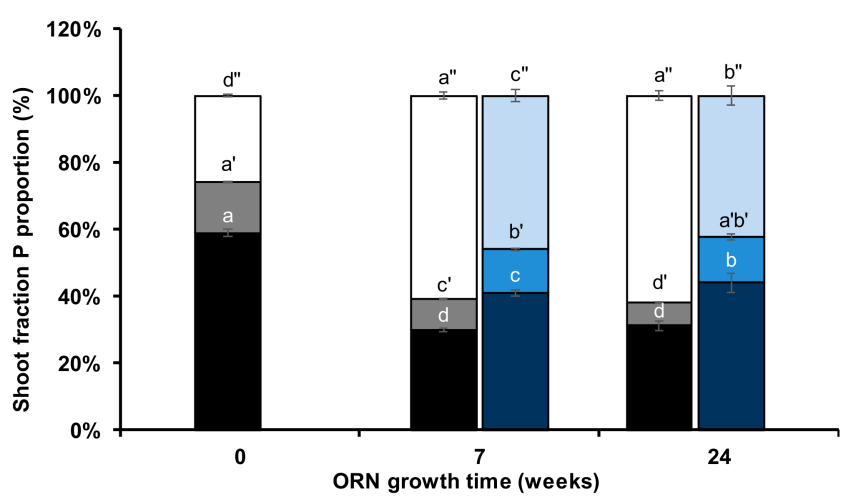

(b)

Figure 3. Subcellular distribution (\%, average and standard error) of manganese (a) and phosphorous (b) (cell wall fraction, black columns (disturbed) and dark blue columns (undisturbed); organelle fraction, grey columns (disturbed) and blue columns (undisturbed) and vacuole contents fraction, white columns (disturbed) and light blue columns (undisturbed)) in shoots of wheat grown in soil with previously grown Ornithopus compressus (ORN), after 0, 7 or 24 weeks. Different letters indicate statistically significant differences $(p<0.05)$ based on Tukey's test.

\subsection{Wheat Shoot Antioxidant Enzymatic Activity}

The activity of antioxidant enzymes in shoot extracts of wheat grown in disturbed soil was generally higher than in those of wheat grown in undisturbed soil (Figure 4).

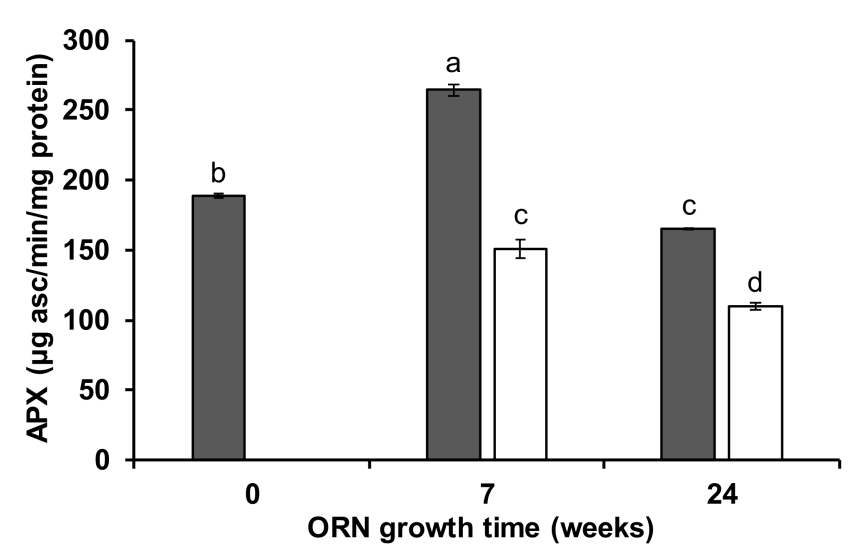

(a)

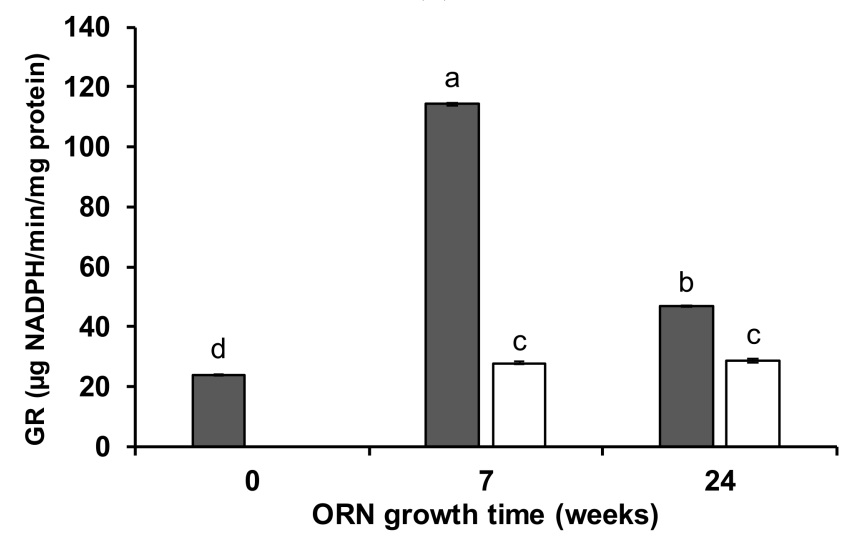

(c)

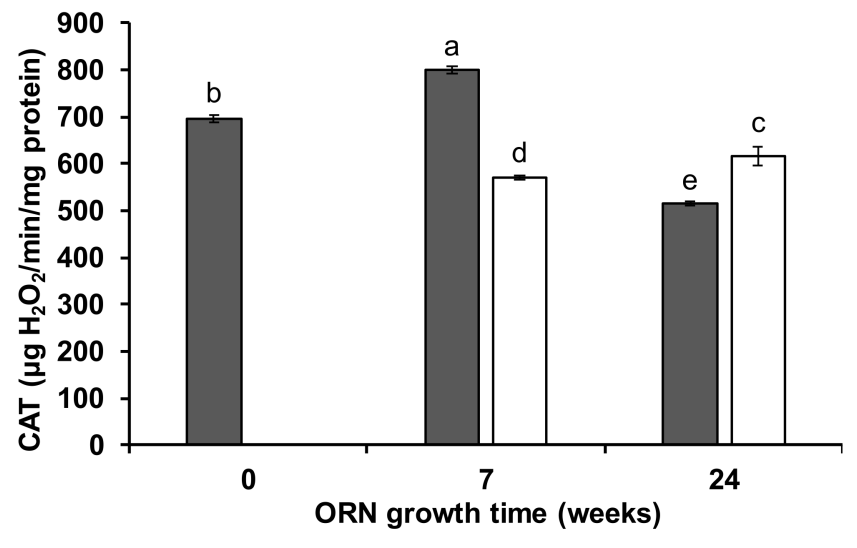

(b)

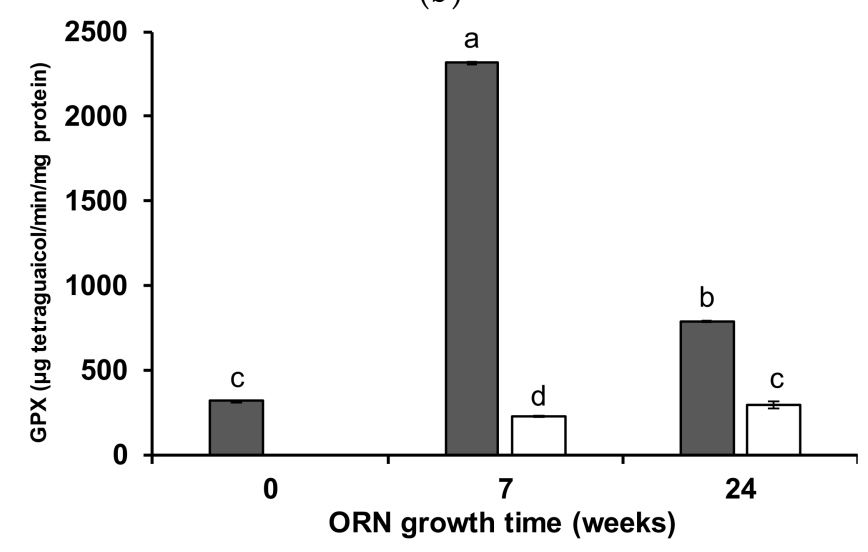

(d)

Figure 4. Cont. 


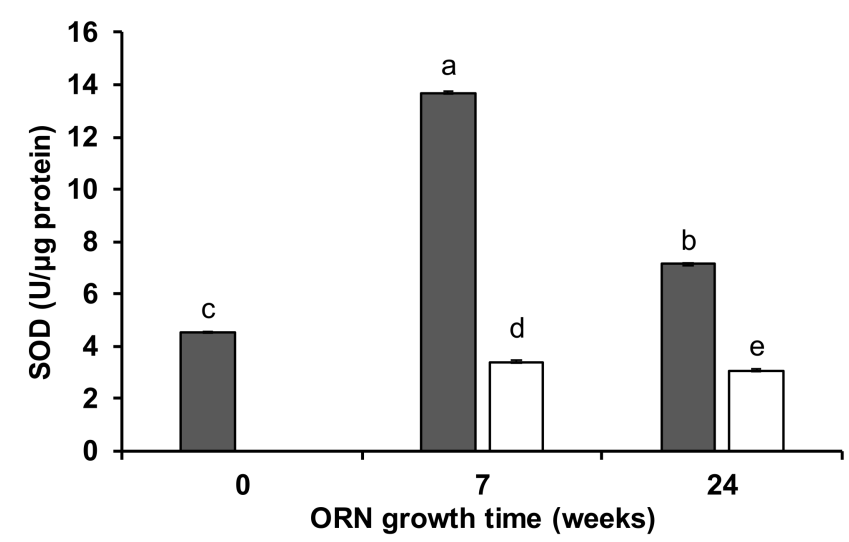

(e)

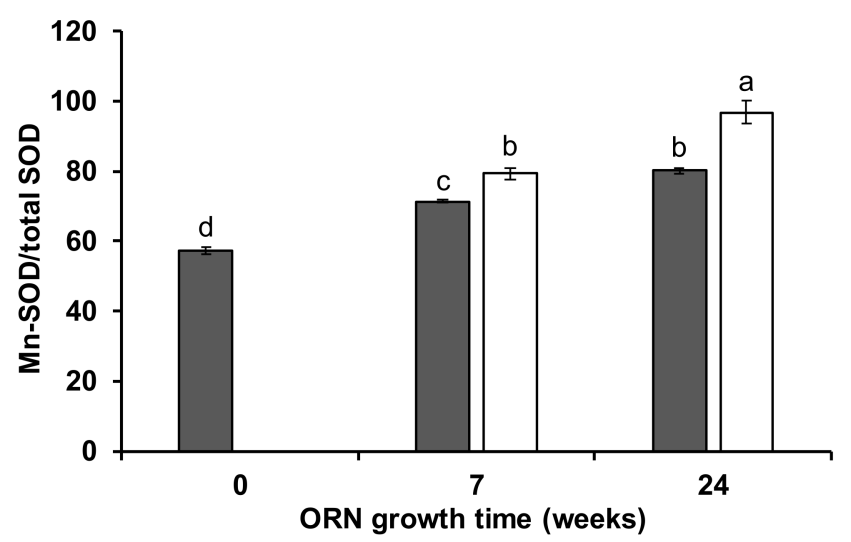

(f)

Figure 4. Activity (average and standard error) of the antioxidant enzymes ascorbate peroxidase (a), catalase (b), glutathione reductase (c), guaiacol peroxidase (d), superoxide dismutase (e) and ratio of manganese superoxide dismutase isoform activity over activity of all isoforms (f) in shoots of wheat grown in disturbed (grey columns) or undisturbed (white columns) soil with previously grown Ornithopus compressus (ORN), after 0, 7 or 24 weeks. Different letters indicate statistically significant differences $(p<0.05)$ based on Tukey's test.

Ascorbate peroxidase (APX) activity was significantly lower in undisturbed soils with 7 and 24 weeks of ORN growth, when compared to respective disturbed soils (Figure 4a). CAT showed a significantly higher activity in shoots of wheat grown in disturbed soil than in undisturbed soil with 7 weeks of ORN growth. However, in soil from 24-week ORN growth this trend was inverted (Figure 4b). Both GR and GPX showed similar patterns of activity (Figure 4c,d). In general, in shoots of wheat grown in soil with no previous ORN growth, that is, under heavy Mn toxicity, these enzymes showed lower activities. In soils with 7 or 24 weeks of ORN growth, soil disturbance increased wheat shoots' enzymatic activity when compared to undisturbed soil. SOD activity in shoots of wheat grown in soil after 0 weeks of ORN growth was significantly lower, when compared to disturbed soil after 7 or 24 weeks, but was higher than the activity determined in shoots of wheat grown in undisturbed soil (Figure 4e). In shoots of wheat grown in disturbed soil after 7 weeks of ORN growth, SOD activity was significantly higher when compared to those grown in disturbed soil after 24 weeks. The ratio of Mn-SOD isozyme activity over the activity of all SOD isozymes increased in the presence of ORN AMF but was higher when wheat was grown in the presence of intact ERM (undisturbed soil). The highest proportion was obtained in shoots of wheat grown in undisturbed soil with previously grown ORN for 24 weeks, indicating increased Mn-SOD activity (Figure 4f).

\section{Discussion}

\subsection{Biochemical Mechanisms Induced by ORN ERM on Wheat under Mn Toxicity}

The use of stress-adapted native plants for a sustainable improvement of crop growth in acidic soils with Mn toxicity shows many advantages, namely increased shoot growth and shoot Mn below toxic levels [24,25]. These benefits were obtained for crops grown in a no-till system, where soil remained undisturbed and the ERM intact $[23,48]$. AMF symbiosis initiated from a fully developed ERM is known to be established in initial stages of plant development and improves crop AM colonization and growth to a greater extent than when initiated from spores or colonized root fragments [22]. Wheat root colonization was previously reported to be $56 \%$ (\% arbuscular colonization) for undisturbed soil but only $14 \%$ for disturbed soil, when in similar conditions to the present study [24]. A full description of the diversity of AMF colonizing wheat roots under these conditions can be found in Brígido et al. [21]. In a previous study, an intact ERM, obtained in the soil by growing ORN, was successful in lowering wheat Mn uptake up to $80 \%$, and more than doubled wheat shoot weight [24]. In this study the same magnitude of influence was observed for intact ERM. Furthermore, intact ERM had a significant influence on the 
element content of wheat shoots, favouring $\mathrm{P}$ and lowering $\mathrm{Ca}, \mathrm{Mg}$ and $\mathrm{Mn}$ concentrations. The positive influence of intact ERM on wheat growth was significant, yet the beneficial effects of AMF on wheat shoot essential nutrient composition remains unclear. Increase in P uptake is a well-known advantage of AMF colonization. Although generally dependent on soil P conditions and on the fungi or host species, AMF-mediated increase in P levels, along with increased nitrogen $(\mathrm{N})$ intake, can be considered the main promoters of plant growth [49,50]. Plant mineral nutrition of other elements has been less studied and shows a great variability in results [51-53]. However, a general improvement in plant nutrition can be attributed to symbiotic AMF [54] and, in acidic soils, maize mycorrhization induced either a positive or no response [55]. Nevertheless, almost $90 \%$ of studies on the influence of plant mycorrhization are performed in laboratory conditions with a single fungal symbiont species [56], which seldom represents responses in natural conditions. Taking advantage of naturally assembled AMF consortiums under toxic Mn levels, the present study detected a decrease in shoot $\mathrm{Mn}$ concentrations accompanied by a decrease in Ca and $\mathrm{Mg}$ levels, either by (i) ERM-induced decrease in element uptake, (ii) reduced root-to-shoot translocation, and/or (iii) shoot element remobilization. Such tight AM host nutritional control is probably also performed at the tissue and cellular level since, under ERM influence, wheat shoots showed a higher proportion of $\mathrm{Mn}$ and $\mathrm{P}$ in the apoplast compartment. Element storage at the apoplast is a common stress-evading strategy in plants under metal toxicity. Tolerance to excess Mn has been linked to increased cation binding to the free carboxylic acid groups in pectins and hemicelluloses of the plant cell walls $[57,58]$. Decrease in vacuolar Mn may also be linked to lower wheat shoot Mn concentrations, since the coaccumulation of $\mathrm{Mn}$ and $\mathrm{P}$ in the vacuole has been determined as a response of wheat cells to high shoot Mn levels, in wheat grown in acidic soil with high Mn concentrations, with no previous Developer [33].

Control of shoot element uptake is concomitant with a generalized lower oxidative stress, indicated by lower antioxidant enzymatic activities in the presence of an earlier AM colonization promoted by an intact ERM when compared with a disrupted ERM. APX and GR are enzymes that belong to the ascorbate-glutathione cycle (Asada-Halliwell cycle), responsible for ascorbate oxidation and the maintenance of reduced glutathione (GSH) pool in the cell. Glutathione is one of the most important non-enzymatic antioxidants to increase in the presence of excessive metal levels, since it is able to directly quench reactive oxygen species (ROS), conjugate with toxic metals and/or act as precursor for phytochelatins production, well-known for the detoxifying activity under heavy metal stress [59]. In the present study, APX and GR activities were lower in the presence of an intact ERM, suggesting that mechanisms other than GSH production are being used as a detoxification strategy. The higher activity of peroxidases that oxidize guaiacol, commonly referred to as GPX, is an indicator of oxidative stress. These peroxidases are located in the cell wall, apoplast and vacuole, and can be soluble or cell-wall bound (ionically and covalently), being generally involved in the reticulation and loosening of the cell wall, lignification and suberization, auxin catabolism and secondary metabolism. On the other hand, APX isoforms are distributed throughout the cytosol, chloroplasts (both stroma and thylakoid membrane), mitochondria and peroxisomes, and modulate subcellular levels of $\mathrm{H}_{2} \mathrm{O}_{2}$ [60]. Under Mn toxicity, indicated by low Mn/Mg ratios $(\leq 20)[1,61]$, and in the absence of a previous Developer, where AM colonization is slower than with intact ERM, wheat shoots display stress-related responses, namely increased vacuole Mn partitioning, altered subcellular distribution of other elements and enhanced activity of enzymes involved in biosynthesis of heavy metal chelator compounds [33]. In the presence of an intact ERM and an earlier AM colonization, Mn uptake is decreased and mainly directed at the shoot apoplast with a possible investment in the mitigation of oxidative stress at cytosol and organelles.

A mechanism of sensitivity to Mn was suggested in Vigna unguiculata in which ascorbate is either formed or transported to the apoplast where it is involved in the oxidation of the bioavailable $\mathrm{Mn}^{2+}$ to $\mathrm{Mn}^{3+}$ and $\mathrm{Mn}^{4+}$, with the simultaneous oxidation of phenolic 
compounds, through the activity of apoplast-bound peroxidases. This process culminates in the formation of brown spots, which are zones of oxidized phenols and excess Mn [62]. In the present work, early AM colonization, granted by intact ERM, appears also to increase cell wall Mn levels in wheat shoots.

The activity of SOD manganese isoform has been described to increase under Mn toxicity [63]. In Lolium perenne, Mn excess induced a higher gene expression of Mn- and $\mathrm{Cu} / \mathrm{Zn}$-SOD isoforms in both tolerant and sensitive cultivars [64]. In Lycopersicon esculentum, excess Mn induced increased activities of mitochondrial Mn- and cytosolic Cu/Zn-SOD isoforms [65], and in Phaseolus vulgaris, this increase was timed with an increase in APX activity and a decrease in ascorbate, which preceded the beginning of leaf chlorosis [66]. In the present study, Mn-SOD activity seemed to be influenced by the presence of an intact ERM, which indicates a possible role for this enzyme in the detoxification mechanisms induced by ORN ERM in wheat grown in acidic soil with Mn toxicity.

An unexpected low activity was detected in antioxidant enzymes from extracts of wheat grown with no previous developer (i.e., 0 weeks of ORN AMF growth). In this treatment, oxidative stress derived from Mn toxicity might have affected enzymatic performance, as was observed in wheat developed under conditions of excess Mn [33]. In fact, the activity of the enzymes analysed was differently affected by the imposed treatments, which might indicate the influence of different levels of simultaneous conditions, such as the stress of high Mn levels and plant growth stimulation by intact ERM.

\subsection{Maintenance of ERM Protective Properties during Mediterranean Summer}

Summer conditions in the Mediterranean are well-known for maximum air temperatures above $30^{\circ} \mathrm{C}$ and very limited water availability, deeply influencing plant soil coverage and crop growth. Despite these extreme conditions, AMF ERM is able to persist in the soil and maintain its colonization capability [34]. In the present study, ERM was kept intact during Mediterranean summer conditions, allowing not only the preservation of its infectivity but also the protective effect of an early AMF crop colonization. This protection was provided by comparable biochemical mechanisms, influencing similar wheat shoot DW, element composition and subcellular distribution and antioxidant enzymes activities, in comparison to a freshly developed ERM. Nevertheless, some parameters (e.g., shoot $\mathrm{Ca}$ and $\mathrm{Mg}$ levels or CAT, APX, GPX and SOD activities) showed small variations, which suggests that, even though infectivity is maintained, AMF assemblage structure might change during the summer period [67]. This, however, does not seem to greatly affect its effectiveness in protecting wheat against Mn toxicity, when grown in acidic soil.

This is the first report on the biochemical characterization of wheat colonized by a recently developed ERM (7 weeks) or by an older ERM (24 weeks), which survived Mediterranean summer conditions under Mn toxicity conditions. This knowledge can be applied to the development of sustainable agronomic practices by allowing the maintenance of soil productivity conditions between seasons and enhanced protection against Mn toxicity in acidic soils to crops grown in different seasons.

\section{Conclusions}

ORN growth in acidic soils can promote wheat growth by improving soil biological conditions and reducing the harmful effects of Mn toxicity, through the development of a beneficial arbuscular mycorrhizal ERM network that allows AM colonization in earlier stages of wheat development. In this study, some of the biochemical mechanisms behind this protective effect were identified at two crop growth seasons, provided that ERM structure is maintained. Earlier wheat AM colonization promoted by the intact ERM, as preferential AMF inoculum source, can alter Mn and P subcellular distribution and manage wheat shoot oxidative response to Mn stress. The hot and dry Mediterranean summer conditions did not significantly affect ERM colonizing ability, or the biochemical mechanisms activated in wheat. The establishment of local stress-adapted plant/AMF symbiosis units, as Developer plants, allied to a no-tillage practice, can provide an impor- 
tant contribution for the development of environmentally safer agricultural techniques and the cultivation of soils that otherwise are not suitable for wheat growth due to limitations imposed by Mn toxicity.

Supplementary Materials: The following are available online at https:/ / www.mdpi.com/article/10 .3390/agronomy11040748/s1.

Author Contributions: Conceptualization, J.M.S.F., D.M.T., A.P.P., I.B., P.B. and M.C.; data curation, J.M.S.F. and P.B.; formal analysis, J.M.S.F. and P.B.; funding acquisition, D.M.T., A.P.P., I.B. and M.C.; investigation, J.M.S.F.; methodology, J.M.S.F., D.M.T., A.P.P., I.B., P.B. and M.C.; project administration, M.C.; resources, D.M.T., A.P.P., I.B. and M.C.; writing-original draft, J.M.S.F.; writing-review and editing, J.M.S.F., D.M.T., A.P.P., I.B., P.B. and M.C. All authors have read and agreed to the published version of the manuscript.

Funding: This study was partially funded by Fundo Europeu de Desenvolvimento Regional (FEDER), Programa Operacional Regional Alentejo 2020 under research contract ALT20-03-0145-FEDER-000039.

Institutional Review Board Statement: Not applicable.

Informed Consent Statement: Not applicable.

Data Availability Statement: The raw data supporting the findings of this study are available from the corresponding author (Jorge M. S. Faria) upon reasonable request.

Acknowledgments: The authors wish to thank Filipa Santos, Manuel Figo, Jorge Nunes, Fátima Candeias and Anabela Cabeça for the technical support and Ana M. Rodrigues from Plant Metabolomics Laboratory at ITQB NOVA for her assistance.

Conflicts of Interest: The authors declare no conflict of interest.

\section{References}

1. Goss, M.J.; Carvalho, M.J.G.P.R. Manganese toxicity: The significance of magnesium for the sensitivity of wheat plants. Plant Soil 1992, 139, 91-98. [CrossRef]

2. Goss, M.J.; Carvalho, M.J.G.P.R.; Cosimini, V.; Fearnhead, M.L. An approach to the identification of potentially toxic concentrations of manganese in soils. Soil Use Manag. 1992, 8, 40-43. [CrossRef]

3. Carvalho, M.; Goss, M.J.; Teixeira, D. Manganese toxicity in Portuguese Cambisols derived from granitic rocks: Causes, limitations of soil analyses and possible solutions. Revista de Ciências Agrárias 2015, 38, 518-527. [CrossRef]

4. Millaleo, R.; Diaz, M.R.-; Ivanov, A.G.; Mora, M.; Alberdi, M. Manganese as essential and toxic element for plants: Transport, accumulation and resistance mechanisms. J. Soil Sci. Plant Nutr. 2010, 10, 470-481. [CrossRef]

5. George, E.; Horst, W.J.; Neumann, E. Chapter 17-Adaptation of plants to adverse chemical soil conditions. In Marschner's Mineral Nutrition of Higher Plants, 3rd ed.; Marschner, P., Ed.; Academic Press: San Diego, CA, USA, 2012; pp. 409-472. ISBN 978-0-12384905-2.

6. Goulding, K.W.T. Soil acidification and the importance of liming agricultural soils with particular reference to the United Kingdom. Soil Use Manag. 2016, 32, 390-399. [CrossRef]

7. Khabaz-Saberi, H.; Setter, T.L.; Waters, I. Waterlogging Induces High to Toxic Concentrations of Iron, Aluminum, and Manganese in Wheat Varieties on Acidic Soil. J. Plant Nutr. 2006, 29, 899-911. [CrossRef]

8. Davis, J. Soil pH and magnesium effects on manganese toxicity in peanuts. J. Plant Nutr. 1996, 19, 535-550. [CrossRef]

9. De Vargas, J.P.; dos Santos, D.R.; Bastos, M.C.; Schaefer, G.; Parisi, P.B. Application forms and types of soil acidity corrective: Changes in depth chemical attributes in long term period experiment. Soil Tillage Res. 2019, 185, 47-60. [CrossRef]

10. Wang, C.; Li, W.; Yang, Z.; Chen, Y.; Shao, W.; Ji, J. An invisible soil acidification: Critical role of soil carbonate and its impact on heavy metal bioavailability. Sci. Rep. 2015, 5, 12735. [CrossRef]

11. Jiang, Y.; Wang, W.; Wang, E.; Xie, Q.; Liu, N.; Liu, L.; Wang, D.; Zhang, X.; Yang, C.; Chen, X.; et al. Plants transfer lipids to sustain colonization by mutualistic mycorrhizal and parasitic fungi. Science 2017, 356, 1172-1175. [CrossRef]

12. Bonfante, P.; Genre, A. Mechanisms underlying beneficial plant-fungus interactions in mycorrhizal symbiosis. Nat. Commun. 2010, 1, 48. [CrossRef]

13. Cabral, L.; Soares, C.R.F.S.; Giachini, A.J.; Siqueira, J.O. Arbuscular mycorrhizal fungi in phytoremediation of contami-nated areas by trace elements: Mechanisms and major benefits of their applications. World J. Microbiol. Biotechnol. 2015, 31, 1655-1664. [CrossRef]

14. Pellegrino, E.; Öpik, M.; Bonari, E.; Ercoli, L. Responses of wheat to arbuscular mycorrhizal fungi: A meta-analysis of field studies from 1975 to 2013. Soil Biol. Biochem. 2015, 84, 210-217. [CrossRef]

15. Oldroyd, G.E.D. Speak, friend, and enter: Signalling systems that promote beneficial symbiotic associations in plants. Nat. Rev. Genet. 2013, 11, 252-263. [CrossRef] 
16. Hildebrandt, U.; Regvar, M.; Bothe, H. Arbuscular mycorrhiza and heavy metal tolerance. Phytochemistry 2007, 68, 139-146. [CrossRef]

17. Sudová, R.; Doubková, P.; Vosatka, M. Mycorrhizal association of Agrostis capillaris and Glomus intraradices under heavy metal stress: Combination of plant clones and fungal isolates from contaminated and uncontaminated substrates. Appl. Soil Ecol. 2008, 40, 19-29. [CrossRef]

18. Krishnamoorthy, R.; Kim, C.-G.; Subramanian, P.; Kim, K.-Y.; Selvakumar, G.; Sa, T.-M. Arbuscular Mycorrhizal Fungi Community Structure, Abundance and Species Richness Changes in Soil by Different Levels of Heavy Metal and Metalloid Concentration. PLoS ONE 2015, 10, e0128784. [CrossRef]

19. Khan, A.G. Role of soil microbes in the rhizospheres of plants growing on trace metal contaminated soils in phytoreme-diation. J. Trace Elem. Med. Biol. 2005, 18, 355-364. [CrossRef]

20. Wei, Y.; Su, Q.; Sun, Z.; Shen, Y.; Li, J.; Zhu, X.; Hou, H.; Chen, Z.; Wu, F.C. The role of arbuscular mycorrhizal fungi in plant uptake, fractions, and speciation of antimony. Appl. Soil Ecol. 2016, 107, 244-250. [CrossRef]

21. Brígido, C.; van Tuinen, D.; Brito, I.; Alho, L.; Goss, M.J.; Carvalho, M. Management of the biological diversity of AM fungi by combination of host plant succession and integrity of extraradical mycelium. Soil Biol. Biochem. 2017, 112, 237-247. [CrossRef]

22. Brito, I.; Goss, M.; Alho, L.; Brígido, C.; Van Tuinen, D.; Félix, M.; Carvalho, M. Agronomic management of AMF functional diversity to overcome biotic and abiotic stresses-The role of plant sequence and intact extraradical mycelium. Fungal Ecol. 2019, 40, 72-81. [CrossRef]

23. Brito, I.; Goss, M.J.; de Carvalho, M.; Chatagnier, O.; van Tuinen, D. Impact of tillage system on arbuscular mycorrhiza fungal communities in the soil under Mediterranean conditions. Soil Tillage Res. 2012, 121, 63-67. [CrossRef]

24. Brito, I.; Carvalho, M.; Alho, L.; Goss, M. Managing arbuscular mycorrhizal fungi for bioprotection: Mn toxicity. Soil Biol. Biochem. 2014, 68, 78-84. [CrossRef]

25. Alho, L.; Carvalho, M.; Brito, I.; Goss, M. The effect of arbuscular mycorrhiza fungal propagules on the growth of subterranean clover (Trifolium subterraneumL.) under Mn toxicity inex situexperiments. Soil Use Manag. 2015, 31, 337-344. [CrossRef]

26. Campos, C.; Carvalho, M.; Brígido, C.; Goss, M.J.; Nobre, T. Symbiosis Specificity of the Preceding Host Plant Can Dominate but Not Obliterate the Association Between Wheat and Its Arbuscular Mycorrhizal Fungal Partners. Front. Microbiol. 2018, 9, 2920. [CrossRef]

27. Campos, C.; Nobre, T.; Goss, M.J.; Faria, J.; Barrulas, P.; Carvalho, M. Transcriptome Analysis of Wheat Roots Reveals a Differential Regulation of Stress Responses Related to Arbuscular Mycorrhizal Fungi and Soil Disturbance. Biology 2019, 8, 93. [CrossRef]

28. Spagnoletti, F.N.; Balestrasse, K.; Lavado, R.S.; Giacometti, R. Arbuscular mycorrhiza detoxifying response against arsenic and pathogenic fungus in soybean. Ecotoxicol. Environ. Saf. 2016, 133, 47-56. [CrossRef]

29. Yang, Y.; Han, X.; Liang, Y.; Ghosh, A.; Chen, J.; Tang, M. The Combined Effects of Arbuscular Mycorrhizal Fungi (AMF) and Lead $(\mathrm{Pb})$ Stress on $\mathrm{Pb}$ Accumulation, Plant Growth Parameters, Photosynthesis, and Antioxidant Enzymes in Robinia pseudoacacia L. PLoS ONE 2015, 10, e0145726. [CrossRef]

30. Ma, Y.; Oliveira, R.S.; Freitas, H.; Zhang, C. Biochemical and Molecular Mechanisms of Plant-Microbe-Metal Interactions: Relevance for Phytoremediation. Front. Plant Sci. 2016, 7, 918. [CrossRef]

31. Gamalero, E.; Lingua, G.; Berta, G.; Glick, B.R. Beneficial role of plant growth promoting bacteria and arbuscular mycorrhizal fungi on plant responses to heavy metal stress. Can. J. Microbiol. 2009, 55, 501-514. [CrossRef]

32. Aghababaei, F.; Raiesi, F. Mycorrhizal fungi and earthworms reduce antioxidant enzyme activities in maize and sunflower plants grown in Cd-polluted soils. Soil Biol. Biochem. 2015, 86, 87-97. [CrossRef]

33. Faria, J.M.; Teixeira, D.M.; Pinto, A.P.; Brito, I.; Barrulas, P.; Alho, L.; Carvalho, M. Toxic levels of manganese in an acidic Cambisol alters antioxidant enzymes activity, element uptake and subcellular distribution in Triticum aestivum. Ecotoxicol. Environ. Saf. 2020, 193, 110355. [CrossRef]

34. Brito, I.; De Carvalho, M.; Goss, M. Summer survival of arbuscular mycorrhiza extraradical mycelium and the potential for its management through tillage options in Mediterranean cropping systems. Soil Use Manag. 2011, 27, 350-356. [CrossRef]

35. Li, C.-C.; Dang, F.; Cang, L.; Zhou, D.-M.; Peijnenburg, W.J. Internal distribution of Cd in lettuce and resulting effects on Cd trophic transfer to the snail: Achatina fulica. Chemosphere 2015, 135, 123-128. [CrossRef]

36. Dandan, L.; Dongmei, Z.; Peng, W.; Nanyan, W.; Xiangdong, Z. Subcellular Cd distribution and its correlation with antioxidant enzymatic activities in wheat (Triticum aestivum) roots. Ecotoxicol. Environ. Saf. 2011, 74, 874-881. [CrossRef]

37. Islam, F.; Yasmeen, T.; Ali, Q.; Ali, S.; Arif, M.S.; Hussain, S.; Rizvi, H. Influence of Pseudomonas aeruginosa as PGPR on oxidative stress tolerance in wheat under Zn stress. Ecotoxicol. Environ. Saf. 2014, 104, 285-293. [CrossRef]

38. Bradford, M.M. A rapid and sensitive method for the quantitation of microgram quantities of protein utilizing the principle of protein-Dye binding. Anal. Biochem. 1976, 72, 248-254. [CrossRef]

39. Li, Y.; Sun, H.; Li, H.; Yang, L.; Ye, B.; Wang, W. Dynamic changes of rhizosphere properties and antioxidant enzyme responses of wheat plants (Triticum aestivum L.) grown in mercury-contaminated soils. Chemosphere 2013, 93, 972-977. [CrossRef]

40. Nakano, Y.; Asada, K. Hydrogen Peroxide is Scavenged by Ascorbate-specific Peroxidase in Spinach Chloroplasts. Plant Cell Physiol. 1981, 22, 867-880. [CrossRef]

41. Aebi, H. Catalase in vitro. Methods Enzymol. 1984, 105, 121-126. [CrossRef]

42. Foyer, C.H.; Halliwell, B. The presence of glutathione and glutathione reductase in chloroplasts: A proposed role in ascorbic acid metabolism. Planta 1976, 133, 21-25. [CrossRef] [PubMed] 
43. Rao, M.V.; Paliyath, G.; Ormrod, D.P. Ultraviolet-B- and Ozone-Induced Biochemical Changes in Antioxidant Enzymes of Arabidopsis thaliana. Plant Physiol. 1996, 110, 125-136. [CrossRef] [PubMed]

44. Aravind, P.; Prasad, M.N.V. Zinc alleviates cadmium-induced oxidative stress in Ceratophyllum demersum L.: A free floating freshwater macrophyte. Plant Physiol. Biochem. 2003, 41, 391-397. [CrossRef]

45. Beyer, W.F.; Fridovich, I. Assaying for superoxide dismutase activity: Some large consequences of minor changes in conditions. Anal. Biochem. 1987, 161, 559-566. [CrossRef]

46. Srivastava, S.; Dubey, R.S. Manganese-excess induces oxidative stress, lowers the pool of antioxidants and elevates activities of key antioxidative enzymes in rice seedlings. Plant Growth Regul. 2011, 64, 1-16. [CrossRef]

47. Pinto, E.; Aguiar, A.A.R.M.; Ferreira, I.M.P.L.V.O. Influence of Soil Chemistry and Plant Physiology in the Phytoremediation of $\mathrm{Cu}, \mathrm{Mn}$, and Zn. Crit. Rev. Plant Sci. 2014, 33, 351-373. [CrossRef]

48. Brito, I.; Carvalho, M.; Goss, M. Soil and weed management for enhancing arbuscular mycorrhiza colonization of wheat. Soil Use Manag. 2013, 29, 540-546. [CrossRef]

49. Marschner, P. Rhizosphere biology. In Marschner's Mineral Nutrition of Higher Plants, 3rd ed.; Academic Press: Cambridge, MA, USA, 2011; pp. 369-388. ISBN 9780123849052.

50. Faria, J.M.S.; Teixeira, D.; Pinto, A.P.; Brito, I.; Barrulas, P.; Carvalho, M. Arbuscular mycorrhiza inoculum type influences phosphorus subcellular distribution in shoots of wheat grown in acidic soil under sustainable agricultural practices. In Proceedings of the 1st International Electronic Conference on Plant Science, Virtual, 1-15 December 2020; MDPI: Basel, Switzerland, 2020; p. 8596 .

51. Lehmann, A.; Rillig, M.C. Arbuscular mycorrhizal contribution to copper, manganese and iron nutrient concentrations in crops-A meta-analysis. Soil Biol. Biochem. 2015, 81, 147-158. [CrossRef]

52. Cabral, C.; Ravnskov, S.; Tringovska, I.; Wollenweber, B. Arbuscular mycorrhizal fungi modify nutrient allocation and composition in wheat (Triticum aestivum L.) subjected to heat-stress. Plant Soil 2016, 408, 385-399. [CrossRef]

53. Liu, A.; Hamel, C.; Hamilton, R.I.; Ma, B.L.; Smith, D.L. Acquisition of Cu, Zn, Mn and Fe by mycorrhizal maize (Zea mays L.) grown in soil at different $P$ and micronutrient levels. Mycorrhiza 2000, 9, 331-336. [CrossRef]

54. Lemes, E.M.; Rodrigues, G.I.; De Paula, A.D.M.; De Lima, D.T.; Torres, J.L.R. Mycorrhizal associations in Cerrado soils: A review of benefits and management. Aust. J. Crop. Sci. 2016, 10, 1504-1510. [CrossRef]

55. Clark, R.B.; Zeto, S.K. Mineral acquisition by arbuscular mycorrhizal plants. J. Plant Nutr. 2000, 23, 867-902. [CrossRef]

56. Hoeksema, J.D.; Chaudhary, V.B.; Gehring, C.A.; Johnson, N.C.; Karst, J.; Koide, R.T.; Pringle, A.; Zabinski, C.; Bever, J.D.; Moore, J.C.; et al. A meta-analysis of context-dependency in plant response to inoculation with mycorrhizal fungi. Ecol. Lett. 2010, 13, 394-407. [CrossRef]

57. Yang, S.; Yi, K.; Chang, M.M.; Ling, G.Z.; Zhao, Z.K.; Li, X.F. Sequestration of Mn into the cell wall contributes to Mn tolerance in sugarcane (Saccharum officinarum L.). Plant Soil 2019, 436, 475-487. [CrossRef]

58. Zhang, X.-H.; Lin, A.-J.; Gao, Y.-L.; Reid, R.J.; Wong, M.-H.; Zhu, Y.-G. Arbuscular mycorrhizal colonisation increases copper binding capacity of root cell walls of Oryza sativa L. and reduces copper uptake. Soil Biol. Biochem. 2009, 41, 930-935. [CrossRef]

59. Hasanuzzaman, M.; Nahar, K.; Anee, T.I.; Fujita, M. Glutathione in plants: Biosynthesis and physiological role in envi-ronmental stress tolerance. Physiol. Mol. Biol. Plants 2017, 23, 249-268. [CrossRef]

60. Veljović Jovanović, S.; Kukavica, B.; Vidović, M.; Morina, F.; Menckhoff, L. Class III peroxidases: Functions, localization and redox regulation of isoenzymes. In Antioxidants and Antioxidant Enzymes in Higher Plants; Gupta, D.K., Palma, J.M., Corpas, F.J., Eds.; Springer International Publishing: Cham, Switzerland, 2018; pp. 269-300. ISBN 978-3-319-75088-0.

61. Le Bot, J.; Goss, M.J.; Carvalho, M.J.G.P.R.; Van Beusichem, M.L.; Kirkby, E.A. The significance of the magnesium to manganese ratio in plant tissues for growth and alleviation of manganese toxicity in tomato (Lycopersicon esculentum) and wheat (Triticum aestivum) plants. Plant Soil 1990, 124, 205-210. [CrossRef]

62. Fecht-Christoffers, M.M.; Maier, P.; Iwasaki, K.; Braun, H.P.; Horst, W.J. The role of the leaf apoplast in manganese toxicity and tolerance in cowpea (Vigna Unguiculata L. Walp). In The Apoplast of Higher Plants: Compartment of Storage, Transport and Reactions, The Significance of the Apoplast for the Mineral Nutrition of Higher Plants; Sattelmacher, B., Horst, W.J., Eds.; Springer: Dordrecht, The Netherlands, 2007; pp. 307-321. ISBN 9781402058431.

63. Alscher, R.G.; Erturk, N.; Heath, L.S. Role of superoxide dismutases (SODs) in controlling oxidative stress in plants. J. Exp. Bot. 2002, 53, 1331-1341. [CrossRef]

64. Ribera-Fonseca, A.; Inostroza-Blancheteau, C.; Cartes, P.; Rengel, Z.; Mora, M. Early induction of Fe-SOD gene expression is involved in tolerance to Mn toxicity in perennial ryegrass. Plant Physiol. Biochem. 2013, 73, 77-82. [CrossRef]

65. Shenker, M.; Plessner, O.E.; Tel-Or, E. Manganese nutrition effects on tomato growth, chlorophyll concentration, and superoxide dismutase activity. J. Plant Physiol. 2004, 161, 197-202. [CrossRef]

66. González, A.; Steffen, K.L.; Lynch, J.P. Light and Excess Manganese. Plant Physiol. 1998, 118, 493-504. [CrossRef] [PubMed]

67. Goss, M.J.; Carvalho, M.; Brito, I. The significance of an intact extraradical mycelium and early root colonization in managing arbuscular mycorrhizal fungi. In Functional Diversity of Mycorrhiza and Sustainable Agriculture; Goss, M.J., Carvalho, M., Brito, I., Eds.; Elsevier: Amsterdam, The Netherlands, 2017; pp. 111-130. 